\title{
Comparison of surgical condition in endoscopic sinus surgery using remifentanil combined with propofol, sevoflurane, or desflurane
}

\author{
Hyung-Seok Yoo $^{1}$, Jin Hee Han ${ }^{2}$, Sung Wook Park ${ }^{2}$, and Keon Sik Kim² \\ Department of Anesthesiology and Pain Medicine, ${ }^{1}$ Seoul National University Bundang Hospital, Seongnam, ${ }^{2}$ Kyung Hee University
} Medical Center, Seoul, Korea

Background: Various maneuvers are commonly used to achieve the ideal operative field necessary for successful endoscopic sinus surgery (ESS). There are a few contradictory reports on this subject and the consensus is that propofol anesthesia results in a better or similar surgical field and less or similar amount of bleeding than volatile anesthesia. The aim of this study was to compare the surgical field in patients in whom intravenous anesthesia is used as opposed to balanced general anesthesia.

Methods: Sixty patients undergoing ESS were randomly assigned into three groups, each of which used a different type of anesthesia: propofol/remifentanil (PRO/REM) group, sevoflurane/remifentanil (SEV/REM) group, and desflurane/remifentanil (DES/REM) group. We aimed to maintain the intraoperative mean blood pressure (MBP) at $65 \mathrm{mmHg}$ and the heartrate (HR) at about 75 beats per minute. The quality of visibility of the surgical field was graded, using a validated scoring system, 60 minutes after the start of the operation.

Results: All groups had a similar MBP and mean HR at 60 minutes after the operation started. There was no significant differences among the three groups for surgical grade score $(\mathrm{P}=0.83)$.

Conclusions: In this comparative study of three anesthetic combinations (PRO/REM, SEV/REM, and DES/REM) in patients undergoing ESS with controlled BP and HR, we did not observe any significant differences in the surgical grade scores. (Korean J Anesthesiol 2010; 59: 377-382)

Key Words: Blood loss, Desflurane, Propofol, Remifentanil, Sevoflurane, Sinusitis.

Received: April 6, 2010. Revised: 1st, May 26, 2010; 2nd, July 13, 2010. Accepted: July 16, 2010.

Corresponding author: Keon Sik Kim, M.D., Department of Anesthesiology and Pain Medicine, School of Medicine, Kyung Hee University, Hoegi-dong, Dongdaemun-gu, Seoul 130-702, Korea. Tel: 82-2-958-8601, Fax: 82-2-958-8580, E-mail: keonsik@hanafos.com

(c) This is an open-access article distributed under the terms of the Creative Commons Attribution Non-Commercial License (http:// creativecommons.org/licenses/by-nc/3.0/), which permits unrestricted non-commercial use, distribution, and reproduction in any medium, provided the original work is properly cited. 


\section{Introduction}

Due to the nature of the space in which endoscopic sinus surgery (ESS) is performed, even a little bleeding can adversely affect the surgeon's ability to visualize the region to be operated. Increased bleeding results in further difficulties in obtaining an adequate surgical field. As a result, the operation become more difficult and takes more time.

Various attempts have been made to improve the surgical field, such as positioning the patient in reverse Trendelenburg, decongesting the nose, infiltrating the lateral nasal wall with lidocaine and epinephrine, or using the hypotensive anesthesia technique $[1,2]$.

There are a few contradictory reports on this subject but the consensus is that propofol anesthesia results in a better or similar surgical field $[2,3]$ and less or similar amount of bleeding [2,4-6] than does volatile anesthesia. The aim of this study was to either confirm or repudiate the findings of previous authors and to investigate the effects of the three types of anesthesia in the surgical field of ESS, with total intravenous anesthesia (TIVA) with propofol/remifentanil, balanced general anesthesia with sevoflurane/remifentanil and desflurane/remifentanil under controlled mean blood pressure (MBP) and heart rate (HR).

\section{Materials and Methods}

With approval from the hospital ethics committee, we recruited 60 patients between the ages of 18 and 60 years who were American Society of Anesthesiologists physical status I and II and were also undergoing elective ESS. The patients were randomly assigned to one of three protocols and then underwent ESS under general anesthesia performed by a single surgeon at a hospital-based surgery center. The exclusion criteria included: body mass index $(\mathrm{BMI}) \geq 30.0$, history of alcohol and drug abuse, pregnancy, medication known to affect minimum alveolar anesthetic concentration (MAC), communication problems, and allergic fungal sinusitis or nasal polyposis ( $>3$ polyps). Allergic fungal sinusitis or nasal polyposis increases inflammation and vascularity; both of these conditions are related to a higher surgical grade score. Written consent for the study was obtained from each patient. Randomization was achieved through selection of an unmarked envelope revealing the study path immediately before induction. Patients were assigned by block randomization to receive one of three anesthetic combinations $(n=20$ patients each group): TIVA with propofol/remifentanil group (PRO/REM), balanced general anesthesia with sevoflurane/ remifentanil group (SEV/REM) and desflurane/remifentanil group (DES/REM).

Thirty minutes before surgery, patients were given 0.2 mg glycopyrrolate intramuscularly. The clinical monitoring included electrocardiography, pulse oximetry, temperature, noninvasive blood pressure, and bispectral index monitor (A2000 BIS XP, Aspect Medical System Inc., Norwood, MA, USA). The patients in the three groups received target concentration infusion (TCI, Orchestra ${ }^{\circledR}$, Base Primea, Fresinius Vial, France) for maintenance of anesthesia. The patient's age and weight were entered into the TCI unit so that the target propofol and remifentanil concentrations could be set. Remifentanil TCI was started at $3 \mathrm{ng} / \mathrm{ml}$. After remifentanil reach target concentration, the inhalation groups (SEV/REM and DES/REM) received propofol (2.0 sevoflurane $2.0 \mathrm{mg} / \mathrm{kg}$ ) for induction followed by sevoflurane 2.0 vol\% or desflurane 5.0 vol\%). The PRO/REM group received propofol (initial target plasma concentration, $4.0 \mu \mathrm{g} / \mathrm{ml}$ ) for maintence of anesthesia. During induction, the patients were ventilated with $100 \%$ oxygen. After loss of the eyelash reflex and verbal response, a bolus dose of rocuronium $0.7 \mathrm{mg} / \mathrm{kg}$ was administered for muscular paralysis. The trachea was intubated and the lungs were mechanically ventilated to achieve an end-tidal $\mathrm{CO}_{2}$ concentration of 25-35 mmHg with $50 \% \mathrm{~N}_{2} \mathrm{O}$ in oxygen. The end-tidal sevoflurane and desflurane concentrations, as well as the propofol and remifentanil maintenance target infusions were adjusted to maintain an adequate depth of anesthesia, as judged by clinical signs and hemodynamic responses to surgical stimuli, and to maintain blood pressure.

In the inhalation group, anesthesia was maintained with sevoflurane (end-tidal concentrations of $0.8-2.0 \%$ ) or desflurane (end-tidal concentrations of 3.0-6.0\%). The target-controlled infusion rate of remifentanil was at $1-3 \mathrm{ng} / \mathrm{ml}$. In the PRO/REM group, propofol was administered via target-controlled infusion to $2-4 \mu \mathrm{g} / \mathrm{ml}$ and remifentanil infusion was set at $1-3 \mathrm{ng} / \mathrm{ml}$.

We aimed to maintain the intraoperative MBP at $65 \mathrm{mmHg}$, $\mathrm{HR}$ at about 75 beats per minute and bispectral index value from 40 to 60 . If the systolic blood pressure fell below $75 \mathrm{mmHg}$, a $5 \mathrm{mg}$ bolus of intravenous (IV) ephedrine was given. No other drugs were administered to control blood pressure.

The propofol, sevoflurane, or desflurane was discontinued and remifentanil and $\mathrm{N}_{2} \mathrm{O}$ were stopped right after the termination of the surgery. Once respiration and response to verbal command were adequate, patients were endotracheally extubated.

In most cases, the syringe device for the propofol infusion were set up and present even when the patient was receiving inhalation anesthesia. This was to prevent surgeons from knowing which kind of method of anesthesia we are providing. After 60 minutes from the start of the operation, the surgeon provided numerical assessments of the operative conditions (primarily in relation to the amount of bleeding and its effect on visibility), and identified the sinus being treated. Surgical 
field was scored using the scale that was originally described by Fromme et al. [7] and then subsequently adapted by Boezaart et al. [8]. Appendix 1 shows the surgical grade scoring system designed specifically for use with ESS. In addition, we documented data regarding the extent of the surgery, the LundMackay (LM) computed tomography (CT) score (Appendix 2 ), the total operating time, total anesthetic time, surgical condition, volume of crystalloid given and the use of ephedrine.

Data were analyzed with the use of SAS ${ }^{\circledR}$ (version 9.2, SAS Institute, Cary, NC, USA). After normality test was conducted, age, volume, initial HR, BMI, operation time and anesthesia time, not showing normal distribution were examined with Kruskal-Wallis test, a non-parametric one-way ANOVA test and MBP at initial, 30 minutes and 60 minutes, HR at 30 minutes and 60 minutes with normal distribution were tested with ANOVA. As scores are ordinal scales, non-parametric analysis was performed, and Kruskal-Wallis test was conducted to determine differences of scores among the drugs. The friedman test was used to determine differences of scores following use of ephedrine and the spearman correlation test was performed to analyze the correlations of age, use of ephedrine and scores of each group, by using Fisher's exact test. Comparisons were considered significant if $\mathrm{P}<0.05$.

\section{Results}

Among the three groups, there were no significant differences in the mean total surgical time, nor were there significant differences in the characteristics of the patients, duration of operation, crystalloid requirement and use of ephedrine (Table 1). The three groups were similar in terms of their mean LM CT score (Table 1). None of the groups had significant differences in MBP and HR throughout the operation (Table 2). There were no significant differences among the three groups for surgical grade score (Table 2).

\section{Discussion}

To obtain a relatively bloodless field in order to optimize visibility for the surgeon, various maneuvers are commonly used [1,2,9-12]. The concept that anesthesia may contribute to blood loss during surgery is not new; Stankiewicz [13] reported that estimated blood loss was less in patients receiving local anesthesia as opposed to general anesthesia for endoscopic sinus surgery. Surgical condition has been reported, in a statistically significant manner, to be influenced by the type of anesthetics, BP and HR $[2,9,10,12]$. Traditionally, controlled

Table 1. The Characteristics of Patients

\begin{tabular}{lcccc}
\hline \multicolumn{1}{c}{ Variables } & $\begin{array}{c}\text { PRO/REM } \\
(\mathrm{n}=20)\end{array}$ & $\begin{array}{c}\text { SEVO/REM } \\
(\mathrm{n}=20)\end{array}$ & $\begin{array}{c}\text { DES/REM } \\
(\mathrm{n}=20)\end{array}$ & P value \\
\hline Age $(\mathrm{yr})$ & $37(19-58)$ & $43(19-58)$ & $43(19-59)$ & 0.17 \\
Weight $(\mathrm{kg})$ & $65(47-85)$ & $64(49-98)$ & $65(51-82)$ & \\
Height $(\mathrm{cm})$ & $167(154-182)$ & $165(153-183)$ & $166(150-182)$ & $8 / 12$ \\
Sex $(\mathrm{F} / \mathrm{M})$ & $5 / 15$ & $10 / 10$ & $23.2(18.3-30.2)$ & 0.94 \\
BMI $\left(\mathrm{kg} / \mathrm{m}^{2}\right)$ & $23.2(18.9-30.7)$ & $23.5(18.3-31.2)$ & $6.70(2-12)$ & 0.65 \\
LM CT score & $6.8(2-14)$ & $6.1(2-12)$ & $108(90-140)$ & 0.81 \\
Duration of anesthesia $(\mathrm{min})$ & $107(80-160)$ & $109(85-140)$ & $82(60-110)$ & 7 \\
Duration of operation $(\mathrm{min})$ & $83(65-120)$ & $84(70-120)$ & 5 & 0.99 \\
Use of ephedrine $(\mathrm{n})$ & 8 & $670(500-1,000)$ & $677.5(500-1,000)$ & 0.83 \\
Crystalloid requirement $(\mathrm{ml})$ & $642.5(400-800)$ & & 0.86 \\
\hline
\end{tabular}

Values are number of patients (n) or medians (range). PRO: propofol, REM: remifentanil, SEVO: sevoflurane, DES: desflurane, F: female, M: male, LM CT: Lund-Mackay computed tomography.

Table 2. Mean Blood Pressure, Heart Rate and Surgical Grade Score

\begin{tabular}{llllll}
\hline \multicolumn{2}{c}{ Variable } & $\begin{array}{c}\text { PRO/REM } \\
(\mathrm{n}=20)\end{array}$ & $\begin{array}{c}\text { SEVO/REM } \\
(\mathrm{n}=20)\end{array}$ & $\begin{array}{c}\text { DES/REM } \\
(\mathrm{n}=20)\end{array}$ & P value \\
\hline Mean BP & Initial & $91.3 \pm 11.3$ & $91.1 \pm 12.9$ & $92.2 \pm 11.8$ & 0.95 \\
& $30 \mathrm{~min}$ & $69.3 \pm 6.7$ & $67.1 \pm 5.7$ & $67.4 \pm 6.0$ & 0.47 \\
Heart rate & $60 \mathrm{~min}$ & $69.3 \pm 5.2$ & $67.2 \pm 4.8$ & $67.3 \pm 4.6$ & 0.30 \\
& Initial & $79.1 \pm 13.2$ & $88.0 \pm 21.8$ & $94.4 \pm 20.0$ & 0.81 \\
Surgical grade score & 30 min & $77.1 \pm 15.7$ & $77.1 \pm 10.8$ & $78.2 \pm 10.1$ & 0.95 \\
& & $74.9 \pm 11.8$ & $74.6 \pm 10.7$ & $73.9 \pm 12.1$ & 0.96 \\
\hline
\end{tabular}

Values are expressed as mean \pm SEM or medians (range). Surgical grade score is measured at 60 minutes after the operation started. PRO: propofol, REM: remifentanil, SEVO: sevoflurane, DES: desflurane. 
hypotension is required to reduce the amount of blood loss and provide a dry surgical field, but can cause some problems such as rebound hypertension, reflex tachycardia, vasodilation, organ ischemia and myocardial depression field for ESS. Further, the surgical field has not always been improved as a consequence of MBP reduction [7] and induced hypotension $[8,14,15]$.

Desflurane is known to cause a moderate rise in heart rate, central venous pressure, and pulmonary artery pressure which often does not become apparent at low doses. Cardiac output remains relatively unchanged or slightly depressed with desflurane at 1-2 MAC. Sevoflurane decreases systemic vascular resistance and arterial blood pressure slightly less than desflurane. Sevoflurane causes little, if any, rise in heartrate, and patient's cardiac output is not maintained as well as it is with desflurane [16]. Despite the slightly different cardiovascular system effects between these two inhalation agents, it is reported that desflurane, sevoflurane or isoflurane combined with remifentanil provided adequate induced hypotension (MAP 60-70 mmHg) and similar surgical conditions during tympanoplasty [17]. Similarly, there are no significant differences between SEV/REM and DES/REM groups in our study.

Inhalation agents have a dose-dependent decrease in systemic vascular resistance which leads to the reduction in blood pressure [16]. This property can cause a capillary bleeding despite that systolic blood pressure is low [9]. Wormald et al. [3] suggest that the improvement in surgical grade in the TIVA group appears to be related to an overall reduction in MAP and the patients in the sevoflurane group require more significant reductions in MAP in order to obtain an equivalent surgical field grade score, due to the vasodilatory effect which results in capillary bleeding.

Some studies have reported that propofol produces a better surgical field than inhalational anesthesia in patients undergoing ESS, irrespective of the complexity of surgery $[2,3,9,18]$. Propofol and opioids can depress cerebral blood flow in parallel with depression of cerebral metabolic rate [19]. Thus, reduction of cerebral blood flow with propofol would be expected to decrease blood flow to the ethmoid, sphenoid, and frontal sinuses and potentially diminish bleeding related to arterial inflow.

It is well-known that remifentanil used in all three groups in our study provides excellent intraoperative analgesia and favors prompt emergence without prolonged respiratory depression $[6,20,21]$. The advantage of remifentanil in ESS is that they lower blood pressure through a decrease in cardiac output without peripheral vasodilatation, which results in reducing the capillary bleeding and at the same time provides good endoscopic surgical conditions [6]. The most frequent adverse events encountered when using remifentanil for IV anesthesia are hypotension during induction and hypotension and/or bradycardia during maintenance $[10,22]$. Although bradycardia is a recognized side effect of remifentanil [22], this was not a significant side effect in our study. In order to maintain controlled BP and HR, we did not allow the concomitant use of other cardiovascular medications other than ephedrine.

In this study, the PRO/REM group showed no statistical difference in using cardiovascular medication (IV ephedrine in this study) when compared with the other groups $(\mathrm{P}=0.83)$. Some needs were almost entirely due to the higher incidence of hypotension during the induction and the early maintenance phase of anesthesia (i.e., after position change and before the start of surgery). In such cases, no significant effect was noted with surgical grade score $(\mathrm{P}=0.62)$.

Severity of chronic sinusitis is one of the factors which can affect surgical condition. Ahn et al. [4] reported that the patients with a low-LM score $(\leq 12)$ were not affected by anesthetic methods. In contrast, TIVA resulted in a better surgical condition than conventional balanced anesthesia in the patients with a high-LM score $(>12)$. In our study, there were no statistically significant differences in MBP $(\mathrm{P}=0.30)$, HR ( $\mathrm{P}$ $=0.96)$, and surgical grade scores $(P=0.82)$ among the three groups at 60 minutes after the initiation of the operation and this result may be due to low LM scores in all three groups.

The operation time has also been reported as having an effect on the surgical field [3], which may be due to an increase in vasodilation with operation time as well as an increase in the surface area of the damaged tissue. In our study, we compared the surgical field score at 60 minutes after the initiation of the operation in all three groups to minimize the operation time factor which may contribute to the surgical field condition.

In conclusion, among three different anesthetic combinations (PRO/REM, SEV/REM, and DES/REM) in patients undergoing ESS with controlled BP and HR, we did not observe any significant differences in the surgical grade scores.

\section{References}

1. Leigh JM. The history of controlled hypotension. Br J Anaesth 1975; 47: 745-9.

2. Pavlin JD, Colley PS, Weymuller EA Jr, Van Norman G, Gunn HC, Koerschgen ME. Propofol versus isoflurane for endoscopic sinus surgery. Am J Otolaryngol 1999; 20: 96-101.

3. Wormald PJ, van Renen G, Perks J, Jones JA, Langton-Hewer CD. The effect of the total intravenous anesthesia compared with inhalational anesthesia on the surgical field during endoscopic sinus surgery. Am J Rhinol 2005; 19: 514-20.

4. Ahn HJ, Chung SK, Dhong HJ, Kim HY, Ahn JH, Lee SM, et al. Comparison of surgical conditions during propofol or sevoflurane anaesthesia for endoscopic sinus surgery. Br J Anaesth 2008; 100: 50-4.

5. Eberhart LH, Folz BJ, Wulf H, Geldner G. Intravenous anesthesia provides optimal surgical conditions during microscopic and endoscopic sinus surgery. Laryngoscope 2003; 113: 1369-73. 
6. Manola M, De Luca E, Moscillo L, Mastella A. Using remifentanil and sufentanil in functional endoscopic sinus surgery to improve surgical conditions. ORL J Otorhinolaryngol Relat Spec 2005; 67: 83-6.

7. Fromme GA, MacKenzie RA, Gould AB Jr, Lund BA, Offord KP. Controlled hypotension for orthognathic surgery. Anesth Analg 1986; 65: 683-6.

8. Boezaart AP, van der Merwe J, Coetzee A. Comparison of sodium nitroprusside- and esmolol-induced controlled hypotension for functional endoscopic sinus surgery. Can J Anaesth 1995; 42(5 Pt 1): 373-6.

9. Blackwell KE, Ross DA, Kapur P, Calcaterra TC. Propofol for maintenance of general anesthesia: a technique to limit blood loss during endoscopic sinus surgery. Am J Otolaryngol 1993; 14: 262-6.

10. Degoute CS, Ray MJ, Manchon M, Dubreuil C, Banssillon V. Remifentanil and controlled hypotension; comparison with nitroprusside or esmolol during tympanoplasty. Can J Anaesth 2001; 48: 20-7.

11. Grundmann U, Silomon M, Bach F, Becker S, Bauer M, Larsen B, et al. Recovery profile and side effects of remifentanil-based anaesthesia with desflurane or propofol for laparoscopic cholecystectomy. Acta Anaesthesiol Scand 2001; 45: 320-6.

12. Mengistu AM, Wolf MW, Boldt J, Röhm KD, Suttner SW, Piper SN. Influence of controlled hypotension using esmolol and sodium nitroprusside on natriuretic peptides in patients undergoing endonasal sinus surgery. Eur J Anaesthesiol 2007; 24: 529-34.

13. Stankiewicz JA. Complications in endoscopic intranasal ethmoidectomy: an update. Laryngoscope 1989; 99(7 Pt 1): 686-90.

14. Jacobi KE, Böhm BE, Rickauer AJ, Jacobi C, Hemmerling TM. Moderate controlled hypotension with sodium nitroprusside does not improve surgical conditions or decrease blood loss in endoscopic sinus surgery. J Clin Anesth 2000; 12: 202-7.

15. Lund VJ, Mackay IS. Staging in rhinosinusitus. Rhinology 1993; 31 : 183-4.

16. Morgan GE Jr, Mikhail MS, Murray MJ. Inhalation anesthetics. In: Clinical Anesthsiology. 4th ed. Edited by Morgan GE Jr, Mikhail MS, Murray MJ: New York, McGraw-Hill. 2006, pp 172-3.

17. Dal D, Celiker V, Ozer E, Başgül E, Salman MA, Aypar U. Induced hypotension for tympanoplasty: a comparison of desflurane, isoflurane and sevoflurane. Eur J Anaesthesiol 2004; 21: 902-6.

18. Loop T, Priebe HJ. Recovery after anesthesia with remifentanil combined with propofol, desflurane, or sevoflurane for otorhinolaryngeal surgery. Anesth Analg 2000; 91: 123-9.

19. Haberer JP, Audibert G, Saunier CG, Muller C, Laxenaire MC, Hartemann D. Effect of propofol and thiopentone on regional blood flow in brain and peripheral tissues during normoxia and hypoxia in the dog. Clin Physiol 1993; 13: 197-207.

20. Feldman PL, James MK, Brackeen MF, Bilotta JM, Schuster SV, Lahey AP, et al. Design, synthesis, and pharmacological evaluation of ultrashort- to long-acting opioid analgetics. J Med Chem 1991; 34: 2202-8.

21. Glass PS, Gan TJ, Howell S. A review of the pharmacokinetics and pharmacodynamics of remifentanil. Anesth Analg 1999; 89(4 Suppl): S7-14.

22. Hogue CW Jr, Bowdle TA, O'Leary C, Duncalf D, Miguel R, Pitts M, et al. A multicenter evaluation of total intravenous anesthesia with remifentanil and propofol for elective inpatient surgery. Anesth Analg 1996; 83: 279-85. 
Appendix 1. Surgical Grade Scoring System Designed Specifically for Use in Endoscopic Sinus Surgery

\begin{tabular}{cl}
\hline Grade & \multicolumn{1}{c}{ Assessment } \\
\hline 0 & No bleeding (cadaveric conditions) \\
1 & Slight bleeding - no suctioning required \\
2 & Slight bleeding - occasional suctioning required \\
3 & Slight bleeding - frequent suctioning required; bleeding threatens surgical field a few seconds after suction is removed \\
4 & Moderate bleeding - frequent suctioning required and bleeding threatens surgical field directly after suction is removed \\
5 & Severe bleeding - constant suctioning required; bleeding appears faster than can be removed by suction; surgical field severely \\
& threatened and surgery usually not possible \\
\hline
\end{tabular}

Appendix 2. Lund-Mackay Computed Tomography Staging System

\begin{tabular}{llccc}
\hline & & No abnormality & Partial opacification & Total opacification \\
\hline Anterior ethmoid & $\mathrm{L}$ & 0 & 1 & 2 \\
Posterior ethmoid & $\mathrm{R}$ & 0 & 1 & 2 \\
\multirow{3}{*}{ Maxillary } & $\mathrm{L}$ & 0 & 1 & 2 \\
\multirow{2}{*}{ Frontal } & $\mathrm{R}$ & 0 & 1 & 2 \\
\multirow{3}{*}{ Spehnoid } & $\mathrm{R}$ & 0 & 1 & 2 \\
& $\mathrm{~L}$ & 0 & 1 & 2 \\
& $\mathrm{R}$ & 0 & 1 & 2 \\
& $\mathrm{~L}$ & 0 & 1 & 2 \\
& $\mathrm{R}$ & 0 & 1 & 2 \\
\hline \multirow{2}{*}{ Ostiomeatal complex } & $\mathrm{L}$ & 0 & 1 & 2 \\
& $\mathrm{R}$ & Non- obstructed & & Obstructed \\
\hline
\end{tabular}

